\title{
Comparative analysis of structural valve deterioration and long- term clinical outcomes after bovine pericardial versus porcine bioprosthetic mitral valve replacement
}

\author{
Woojung Kim^, Ho Young Hwang^, Yoonjin Kang^, Ji Seong Kim^, Suk Ho Sohn^, Jae Woong Choi^, \\ Kyung Hwan Kim^ \\ Department of Thoracic and Cardiovascular Surgery, Seoul National University Hospital, Seoul National University College of Medicine, Seoul, \\ Republic of Korea \\ Contributions: (I) Conception and design: HY Hwang; (II) Administrative support: HY Hwang; (III) Provision of study materials or patients: HY \\ Hwang, Y Kang, JS Kim, SH Sohn, JW Choi, KH Kim; (IV) Collection and assembly of data: W Kim, HY Hwang, JW Choi; (V) Data analysis and \\ interpretation: W Kim, HY Hwang; (VI) Manuscript writing: All authors; (VII) Final approval of the manuscript: All authors. \\ Correspondence to: Ho Young Hwang, MD, PhD. Department of Thoracic and Cardiovascular Surgery, Seoul National University Hospital, Seoul \\ National University College of Medicine, 101 Daehak-ro, Chongno-gu, Seoul 03080, Republic of Korea. Email: scalpel@hanmail.net.
}

Background: This study aimed to compare long-term outcomes, including durability, after bovine
pericardial valve replacement with those after porcine mitral valve replacement (MVR).
Methods: We enrolled 309 patients who underwent MV replacement (mean age: $65.8 \pm 11.5$ years; $68.9 \%$
females) with Carpentier-Edwards PERIMOUNT bovine pericardial valves (bovine MVR group, n=241)
or Hancock II porcine bioprosthesis (porcine MVR group, n=68). The mean clinical and echocardiographic
follow-up durations were $81.4 \pm 60.0$ and $57.8 \pm 53.3$ months, respectively. Structural valve deterioration
(SVD) was defined as prosthetic mitral valve $(\mathrm{MV}$ ) regurgitation or stenosis of greater than moderate
degree combined with a motion limitation, tear, or perforation of prosthetic valve leaflet on follow-up
echocardiography. Propensity score $(\mathrm{PS})$-adjusted multivariable analyses were performed. Results: Thirty-day mortality rate was $6.4 \%$ (20/309 patients). SVD occurred in 50 patients (33 and 17 patients in the bovine and porcine MV replacement groups, respectively). Cumulative incidences of SVD at 5,10 , and 15 years were $3.2 \%, 15.9 \%$, and $32.4 \%$, respectively, in the bovine MVR group and $1.9 \%$, $15.3 \%$, and $41.7 \%$, respectively, in the porcine MVR group. Cumulative incidences of SVD in the two groups were not different in competing risk analysis $(\mathrm{P}=0.23)$. Other clinical outcomes including overall survival and cumulative incidences of cardiac death and MV-related events were not statistically significantly different between the groups in PS-adjusted multivariable analyses.

Conclusions: Long-term clinical outcomes including SVD were not different between the bovine and porcine bioprosthesis MVR groups during average 7 years of clinical follow-up after MVR.

Keywords: Mitral valve (MV); heart valve prosthesis; structural valve deterioration (SVD)

Submitted Feb 15, 2021. Accepted for publication May 21, 2021.

doi: $10.21037 /$ jtd-21-281

View this article at: https://dx.doi.org/10.21037/jtd-21-281

\footnotetext{
$\wedge$ ORCID: Woojung Kim, 0000-0001-9530-8638; Ho Young Hwang, 0000-0002-8935-8118; Yoonjin Kang, 0000-0002-2528-173X; Ji Seong Kim, 0000-0003-2908-7130; Suk Ho Sohn, 0000-0001-7391-3415; Jae Woong Choi, 0000-0002-0921-756X; Kyung Hwan Kim, $0000-0002-2718-8758$.
} 


\section{Introduction}

Bioprosthetic valve replacement is a useful option in mitral valve (MV) surgery, having low thromboembolic risks without the need for life-long anticoagulation. Despite advancements in valve technology, the durability of bioprosthetic valves remains an issue, which results in structural valve deterioration (SVD). Several types of bovine pericardial and porcine valves are currently available, and they have been used exclusively based on surgeons' preferences. Although previous studies have demonstrated the long-term clinical outcome and durability of bioprosthetic mitral valve replacement (MVR) (1-3), data directly comparing long-term results after MVR using these two types of valves are scarce. Therefore, this study was conducted to compare long-term results after MVR using Carpentier-Edwards bovine pericardial and Hancock II porcine bioprosthetic valves.

We present the following article in accordance with the STROBE reporting checklist (available at https://dx.doi. org/10.21037/jtd-21-281).

\section{Methods}

\section{Patient characteristics}

The study was approved by the institutional review board of Seoul National University Hospital (IRB No.: 2004-053111 ), and the requirement for patient consent was waived. This study complied with the Declaration of Helsinki. From January 2001 to December 2018, 1,156 patients underwent MVR at our institution. Of these patients, 814 who underwent MVR with mechanical valves and 33 who underwent MVR with other types of tissue valves were excluded. A total of 309 patients who underwent MVR with Carpentier-Edwards PERIMOUNT bovine pericardial valves (Edwards Lifesciences, Irvine, CA, USA; BMVR group, $\mathrm{n}=241$ ) or Hancock II porcine bioprosthesis (Medtronic, Inc., Minneapolis, MN, USA; PMVR group, $\mathrm{n}=68$ ) were enrolled (Figure 1). The mean age at operation was $65.8 \pm 11.5$ years, and $213(68.9 \%)$ were female patients. The BMVR group patients were older, had a smaller body surface area, were more likely to have hypertension, and were less likely to have left ventricular dysfunction than the PMVR group patients, however, not different in Euroscore II (Table 1).

\section{Operative data}

All operations were performed with aorto-bicaval cannulation under moderate hypothermia and cold cardioplegic arrest. The selection of the valve was at the discretion of the attending surgeons. Concomitant procedures included aortic valve surgery $(\mathrm{n}=110,35.6 \%)$, tricuspid valve procedure $(\mathrm{n}=133,43.0 \%)$, arrhythmia surgery $(n=107,34.6 \%)$, and coronary artery bypass grafting $(\mathrm{n}=17,5.5 \%)$. The mean cardiopulmonary bypass and aortic cross-clamp times were $224.2 \pm 76.6$ and $149.1 \pm$ 50.4 minutes, respectively. The aortic cross-clamp time was longer, and more concomitant procedures were performed in the BMVR group than in the PMVR group (Table 2).

\section{Evaluation of early-and long-term clinical outcomes}

Early mortality was defined as death within 30 days of operation. Patients underwent regular postoperative followup at the outpatient clinic at 3- to 6-month intervals. If the patients did not attend the outpatient clinic at the scheduled time, they were contacted through telephone regarding their condition. In addition, the survival data of the patients were obtained based on data from the Korean National Health Insurance. The follow-up ended on February 28, 2020. Routine echocardiographic evaluations were performed before discharge and 6 months to 1 year after surgery. Thereafter, follow-up echocardiography was performed at the discretion of the physician based on patients' symptom and auscultatory findings. The completeness of follow-up was $100 \%$ for survival data and $94.5 \%$ for other outcomes. The mean clinical and echocardiographic follow-up durations were $81.4 \pm 60.0$ and $57.8 \pm 53.3$ months, respectively.

Oral anticoagulants were prescribed to achieve a target international normalized ratio of 2.5-3.0 for 6 months. However, it was prescribed for life in 106 patients (34.3\%) who had mechanical valves in other valve positions or had atrial fibrillation.

Cardiac death was defined as death due to cardiac causes, including sudden death. SVD was defined as intrinsic changes to the xenograft, such as leaflet thickening, calcification, and tear, leading to mitral stenosis with the mean pressure gradient over $6 \mathrm{mmHg}$ or mitral regurgitation of greater than or equal to moderate degree (4-6). Changes in echocardiographic data such as increase of mean pressure gradient or regurgitation due to prosthetic valve endocarditis was excluded. The diagnosis of SVD relied on the aspects of the valve at reoperation and on echocardiographic surveillance. Changes in echocardiographic data at preoperative period, early 


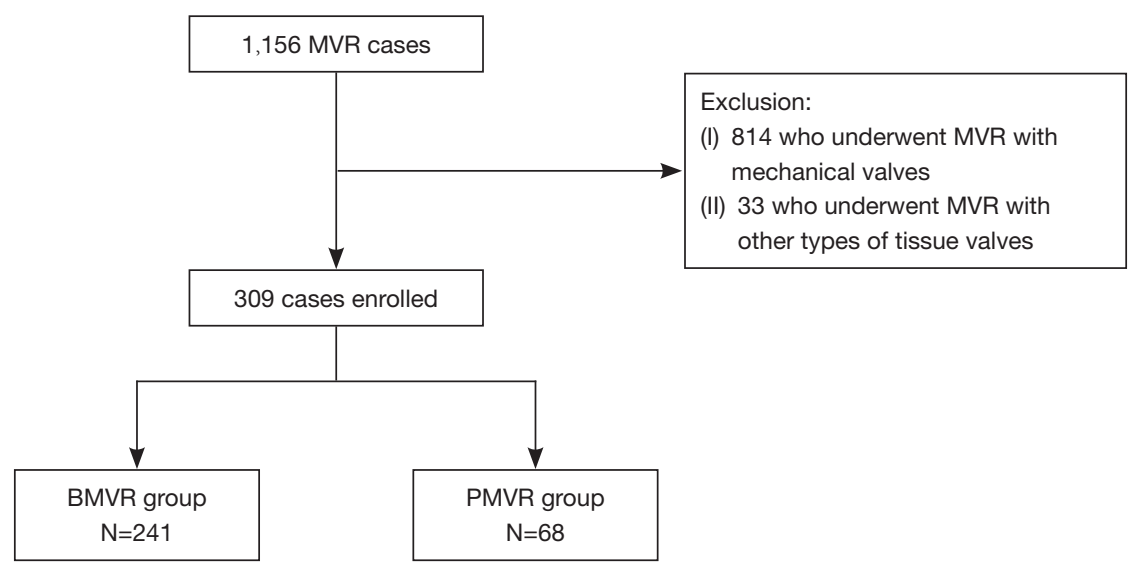

Figure 1 Flowchart of the patient selection process. MVR, mitral valve replacement; BMVR, mitral valve replacement with CarpentierEdwards PERIMOUNT bovine pericardial valves; PMVR, mitral valve replacement with Hancock II porcine bioprostheses.

postoperative period, and last follow-up are presented in the supplementary material (Table S1). Non-structural valve dysfunction (NSVD) was defined as a valvular abnormality without intrinsic valvular dysfunction, such as pannus formation and paravalvular leak. Major bleeding was defined as any bleeding causing death, hospitalization, or permanent injury or necessitating transfusion. Mitral valverelated events (MVREs) were defined as (I) cardiac death; (II) a composite of thromboembolism and major bleeding (CTEB), (III) SVD, (IV) NSVD, (V) prosthetic MV endocarditis, (VI) MV reoperation, and (VII) permanent pacemaker implantation within 14 days following MVR (4).

\section{Statistical analysis}

Statistical analyses were performed using IBM SPSS Statistics for Windows, version 25 (IBM Corp., Armonk, NY, USA), and SAS (version 9.4; SAS Institute Inc., Cary, NC, USA). Student's $t$-test and chi-square test were used for the comparison of continuous and categorical variables, respectively. Survival rates were estimated using the Kaplan-Meier method. Risk factors for overall survival were analyzed using the multivariable Cox proportional hazards model. Cumulative incidences of cardiac death and MVRE were estimated with non-cardiac death as a competing risk. Cumulative incidences of SVD were estimated with all-cause death as a competing risk. Risk factors for longitudinal data of the two groups were analyzed using the Fine-Gray proportional subdistribution hazards model. The proportional hazards assumption was checked using logminus-log plots of survival function for categorical variables or time-dependent covariates in the Cox or Fine-Gray hazards models.

Propensity score (PS)-adjusted analyses were performed to overcome baseline differences between the two groups by including PS as an additional covariate in the multivariable analysis. Preoperative variables such as age, sex, body surface area, smoking, hypertension, diabetes mellitus, body mass index $>25 \mathrm{~kg} / \mathrm{m}^{2}$, history of stroke, chronic obstructive lung disease, chronic renal failure, dialysis, coronary artery disease, dyslipidemia, NYHA class $\geq 3$, previous history of MVR, atrial fibrillation, endocarditis, left ventricular dysfunction (ejection fraction $<50 \%$ ) and Euroscore II and operative variables such as prosthetic valve size, concomitant mitral or aortic valve procedure, arrhythmia surgery, and coronary artery bypass grafting were included in the logistic regression model for PS. Parameters showing a $\mathrm{P}$ value of $<0.10$ in univariate analyses were included in the multivariable analyses. A P value of $<0.05$ indicated statistical significance. Statistical tests were conducted without adjustment for multiple testing because this study was of exploratory nature.

\section{Results}

\section{Early outcomes}

Early mortality occurred in $20(6.4 \%)$ patients. There were no differences in early mortality and postoperative complications between the two groups, except for a lower incidence of reoperation due to bleeding in the BMVR group than in the PMVR group (Table S2). 
Table 1 Preoperative data of the study patients

\begin{tabular}{|c|c|c|c|}
\hline Variables & $\begin{array}{l}\text { BMVR group } \\
\qquad(\mathrm{n}=241)\end{array}$ & $\begin{array}{l}\text { PMVR group } \\
\qquad(n=68)\end{array}$ & $P$ value \\
\hline Age (years) & $66.9 \pm 10.6$ & $61.6 \pm 13.6$ & 0.040 \\
\hline Female, n (\%) & $172(71.4)$ & $41(60.3)$ & 0.081 \\
\hline Body surface area $\left(\mathrm{m}^{2}\right)$ & $1.5 \pm 0.2$ & $1.6 \pm 0.2$ & 0.018 \\
\hline \multicolumn{4}{|l|}{ Risk factors, n (\%) } \\
\hline Smoking & $22(9.1)$ & $8(11.8)$ & 0.52 \\
\hline Hypertension & $65(27.0)$ & $9(13.2)$ & 0.019 \\
\hline Diabetes mellitus & $47(19.5)$ & $12(17.6)$ & 0.73 \\
\hline $\mathrm{BMI} \geq 25 \mathrm{~kg} / \mathrm{m}^{2}$ & $46(19.1)$ & $11(16.2)$ & 0.59 \\
\hline History of stroke & $28(16.2)$ & $9(13.2)$ & 0.55 \\
\hline COPD & $21(8.7)$ & $5(7.4)$ & 0.72 \\
\hline CRF & $33(13.7)$ & $14(20.6)$ & 0.16 \\
\hline ESRD* & $9(3.7)$ & $0(0.0)$ & 0.22 \\
\hline $\begin{array}{l}\text { Coronary artery } \\
\text { disease }\end{array}$ & $28(11.6)$ & $8(11.8)$ & 0.97 \\
\hline Dyslipidemia & $44(18.3)$ & $19(27.9)$ & 0.080 \\
\hline NYHA class $\geq 3$ & $121(50.2)$ & $31(45.6)$ & 0.50 \\
\hline $\begin{array}{l}\text { Previous mitral valve } \\
\text { replacement }\end{array}$ & $39(16.2)$ & $12(17.6)$ & 0.77 \\
\hline Atrial fibrillation & $151(62.7)$ & $42(61.8)$ & 0.89 \\
\hline Endocarditis & $27(11.2)$ & $9(13.2)$ & 0.65 \\
\hline $\begin{array}{l}\text { LV dysfunction } \\
(\mathrm{EF}<50 \%)\end{array}$ & $37(15.4)$ & $20(29.4)$ & 0.008 \\
\hline Euroscore II & $3.7 \pm 4.4$ & $3.7 \pm 3.5$ & 0.89 \\
\hline
\end{tabular}

*, renal failure treated by dialysis or transplantation, which is adapted from the definition of chronic kidney disease by The Kidney Disease: Improving Global Outcomes Work Group. BMVR, mitral valve replacement with Carpentier-Edwards PERIMOUNT bovine pericardial valves; PMVR, mitral valve replacement with Hancock II porcine bioprostheses; BMI, body mass index; COPD, chronic obstructive pulmonary disease; $\mathrm{CRF}$, chronic renal failure; EF, ejection fraction; ESRD, endstage renal disease; LV, left ventricle; NYHA, New York Heart Association.

\section{Long-term survival}

Late death occurred in 140 (45.3\%) patients, including 78 (25.2\%) cardiac deaths during the follow-up. The 5-, 10-, and 15 -year survival rates were $68.8 \%, 54.9 \%$, and $36.5 \%$, respectively. Cumulative incidences of cardiac death at 5,10 , and 15 years were $18.0 \%, 24.2 \%$, and $34.7 \%$, respectively.
Table 2 Operative data of the study patients

\begin{tabular}{|c|c|c|c|}
\hline Variables & $\begin{array}{l}\text { BMVR group } \\
\quad(n=241)\end{array}$ & $\begin{array}{l}\text { PMVR group } \\
\quad(n=68)\end{array}$ & $P$ value \\
\hline CPB time (minutes) & $228.6 \pm 74.5$ & $208.7 \pm 82.4$ & 0.060 \\
\hline ACC time (minutes) & $153.6 \pm 51.0$ & $133.0 \pm 44.9$ & 0.003 \\
\hline \multicolumn{3}{|c|}{ Prosthetic valve size, $\mathrm{n}(\%)$} & 0.13 \\
\hline 21 & $1(0.4)$ & $0(0.0)$ & \\
\hline 23 & $4(1.7)$ & $0(0.0)$ & \\
\hline 25 & $71(29.5)$ & $21(30.9)$ & \\
\hline 27 & $57(23.7)$ & $26(38.2)$ & \\
\hline 29 & $70(29.0)$ & $17(25.0)$ & \\
\hline 31 & $33(13.7)$ & $3(4.4)$ & \\
\hline 33 & $5(2.1)$ & $1(1.4)$ & \\
\hline \multicolumn{4}{|c|}{ Concomitant procedure, n (\%) } \\
\hline $\begin{array}{l}\text { Aortic valve } \\
\text { procedure }\end{array}$ & $99(41.1)$ & $11(16.2)$ & $<0.001$ \\
\hline $\begin{array}{l}\text { Bioprosthetic valve } \\
\text { replacement }\end{array}$ & $92(38.2)$ & $10(14.7)$ & \\
\hline $\begin{array}{l}\text { Mechanical valve } \\
\text { replacement }\end{array}$ & $1(0.4)$ & $1(1.5)$ & \\
\hline Repair & $6(2.5)$ & $0(0.0)$ & \\
\hline $\begin{array}{l}\text { Tricuspid valve } \\
\text { procedure }\end{array}$ & $119(49.4)$ & $14(20.6)$ & $<0.001$ \\
\hline $\begin{array}{l}\text { Bioprosthetic valve } \\
\text { replacement }\end{array}$ & $13(5.4)$ & $3(4.4)$ & \\
\hline $\begin{array}{l}\text { Mechanical valve } \\
\text { replacement }\end{array}$ & $0(0.0)$ & $0(0.0)$ & \\
\hline Repair & $116(48.1)$ & $11(16.2)$ & \\
\hline Arrhythmia surgery & $74(30.7)$ & $33(48.5)$ & 0.006 \\
\hline CABG & $13(5.4)$ & $4(7.4)$ & 0.54 \\
\hline
\end{tabular}

BMVR, mitral valve replacement with Carpentier-Edwards PERIMOUNT bovine pericardial valves; PMVR, mitral valve replacement with Hancock II porcine bioprostheses; ACC, aortic cross clamp; CPB, cardiopulmonary bypass; CABG, coronary artery bypass grafting.

There were no significant differences in the overall survival rates and cumulative incidences of cardiac death between the two groups $(\mathrm{P}=0.59$ and 0.15 , respectively; Table 3 and Figure 2). Risk factors associated with overall survival in the multivariable analysis were age, dyslipidemia, NYHA class $\geq 3, \mathrm{LV}$ dysfunction, Euroscore II and arrhythmia surgery (Table 3). 
Table 3 Univariate and multivariable analyses for the risk factors of overall survival.

\begin{tabular}{|c|c|c|c|c|}
\hline Variables $^{\mathrm{a}}$ & \multicolumn{2}{|c|}{ Univariate analysis } & \multicolumn{2}{|c|}{ PS-adjusted multivariable analysis } \\
\hline Types of valves & $0.670[0.434-1.033]$ & 0.070 & $1.238[0.702-2.183]$ & 0.59 \\
\hline Age (years) & $1.072[1.048-1.097]$ & $<0.001$ & $1.047[1.022-1.073]$ & $<0.001$ \\
\hline Sex & $1.422[0.996-2.031]$ & 0.053 & $0.944[0.556-1.601]$ & 0.83 \\
\hline $1.409<n \leq 1.509$ & $0.422[0.260-0.685]$ & $<0.001$ & $0.535[0.314-0.910]$ & 0.021 \\
\hline $1.509<\mathrm{n} \leq 1.641$ & $0.475[0.296-0.762]$ & 0.002 & $0.617[0.333-1.144]$ & 0.13 \\
\hline $1.641<n$ & $0.763[0.496-1.175]$ & 0.22 & $0.795[0.424-1.489]$ & 0.47 \\
\hline Hypertension & $1.688[1.148-2.482]$ & 0.008 & $1.295[0.820-2.045]$ & 0.27 \\
\hline Coronary artery disease & $2.307[1.483-3.591]$ & $<0.001$ & $1.042[0.570-1.905]$ & 0.89 \\
\hline Dyslipidemia & $0.560[0.346-0.904]$ & 0.018 & $0.487[0.288-0.824]$ & 0.007 \\
\hline NYHA class $\geq 3$ & 1.939 [1.375-2.733] & $<0.001$ & $1.387[0.952-2.022]$ & 0.089 \\
\hline Previous mitral valve replacement & $1.561[1.030-2.350]$ & 0.033 & $0.769[0.476-1.241]$ & 0.28 \\
\hline Endocarditis & 1.939 [1.212-3.101] & 0.006 & $1.545[0.880-2.711]$ & 0.13 \\
\hline LV dysfunction ( $E F<<50 \%$ ) & $1.670[1.133-2.460]$ & 0.010 & $1.681[1.065-2.652]$ & 0.026 \\
\hline Euroscore II & $1.138[1.106-1.170]$ & $<0.001$ & $1.091[1.045-1.138]$ & $<0.001$ \\
\hline Arrhythmia surgery & $0.452[0.306-0.667]$ & $<0.001$ & $0.523[0.334-0.820]$ & 0.005 \\
\hline
\end{tabular}

a , all variables in Table 1 were analyzed and factors that entered into the multivariable analysis were shown. CABG, coronary artery bypass graft; Cl, confidence interval; CRF, chronic renal failure; ESRD, end stage renal disease; EF, ejection fraction; HR, hazard ratio; LV, left ventricle; NYHA, New York Heart Association; PS, propensity score.

\section{Long-term MVREs}

SVD occurred in 50 patients [33 (13.7\%) and 17 (25\%) patients in the BMVR and PMVR groups, respectively] in the study population. SVD resulted in prosthetic valve stenosis, regurgitation, and steno-insufficiency in 28,2 , and 3 patients, respectively, in the BMVR group and in 7, 7, and 3 patients, respectively, in the PMVR group. Cumulative incidences of SVD at 5, 10, and 15 years were $3.1 \%$, $15.5 \%$, and $35.0 \%$, respectively; these were $3.2 \%, 15.9 \%$, and $32.4 \%$, respectively, in the BMVR group and $1.9 \%$, $15.3 \%$, and $41.7 \%$, respectively, in the PMVR group. The competing risk analysis demonstrated that the cumulative incidence of SVD was not significantly different between the two groups ( $\mathrm{P}=0.23$; Table 4 and Figure 3). Euroscore II was associated with SVD in the multivariable analysis (Table 4).
MV reoperations were performed in 34 patients, including 18 reoperations for SVD, which composed of 11 reoperations in the BMVR group and 7 in the PMVR group. Prosthetic valve thrombosis occurred in 8 and 3 patients in the BMVR and PMVR groups, respectively. CTEB occurred in $40(12.9 \%)$ patients during follow-up (32 and 8 in the BMVR and PMVR groups, respectively). There were no differences in the cumulative incidence of CTEB between the 2 groups $(\mathrm{P}=0.66)$. Prosthetic valve endocarditis occurred in 5 and 3 patients in the BMVR and PMVR groups, respectively, without intergroup difference $(\mathrm{P}=0.30)$. Cumulative incidences of MVRE of 5, 10, and 15 years were $30.0 \%, 45.5 \%$, and $65.7 \%$, respectively. There was no significant difference in the cumulative incidence of MVRE between the two groups ( $\mathrm{P}=0.065$; Table 5 and Figure 4). Risk factors associated with MVRE in the multivariable 

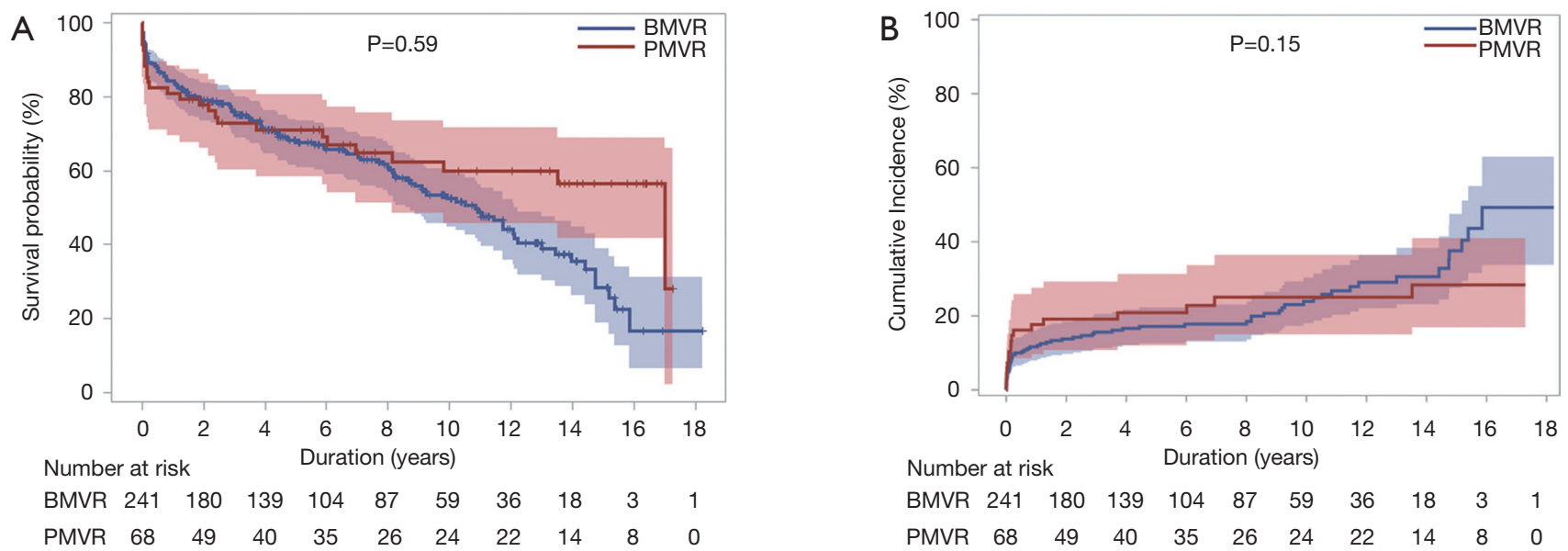

Figure 2 Graphs for long-term survival. (A) Kaplan-Meier curve for overall survival and (B) cumulative incidence of cardiac deaths after MVR with BMVR and PMVR groups. The P values were obtained from Cox proportional hazards and multivariable Fine-Gray proportional subdistribution hazards models for overall survival and cumulative incidence of cardiac deaths, respectively. MVR, mitral valve replacement; BMVR, mitral valve replacement with Carpentier-Edwards PERIMOUNT bovine pericardial valves; PMVR, mitral valve replacement with Hancock II porcine bioprostheses.

Table 4 Univariate and multivariable analyses for the risk factors of structural valve deterioration

\begin{tabular}{|c|c|c|c|c|}
\hline Variables $^{a}$ & \multicolumn{2}{|c|}{ Univariate analysis } & \multicolumn{2}{|c|}{ PS-adjusted multivariable analysis } \\
\hline Types of valves & $1.526[0.889-2.619]$ & 0.13 & $1.555[0.756-3.195]$ & 0.23 \\
\hline Age & $0.971[0.954-0.989]$ & 0.001 & $0.986[0.960-1.013]$ & 0.30 \\
\hline Sex & $0.458[0.215-0.976]$ & 0.043 & $0.547[0.235-1.276]$ & 0.16 \\
\hline Atrial fibrillation & $0.606[0.357-1.028]$ & 0.063 & $0.785[0.400-1.541]$ & 0.48 \\
\hline Euroscore II & $0.879[0.802-0.963]$ & 0.006 & 0.913 [0.838-0.995] & 0.038 \\
\hline Prosthetic valve size & $0.864[0.767-0.974]$ & 0.02 & $0.927[0.806-1.067]$ & 0.29 \\
\hline
\end{tabular}

a , all variables in Table 1 were analyzed and factors that entered into the multivariable analysis were shown. $\mathrm{Cl}$, confidence interval; HR, hazard ratio; NYHA, New York Heart Association; PS, propensity score.

analysis were NYHA class $\geq 3$ and Euroscore II (Table 5).

\section{Discussion}

The present study demonstrated two main findings. First, the cumulative incidence of SVD was not different after bovine pericardial and porcine bioprosthetic MVR over an 18-year postoperative follow-up period. Second, longterm clinical outcomes, including survival and MVRE, were not significantly different between the BMVR and PMVR groups.
Although MV repair has been widely adopted for the surgical treatment of MV disease, MVR remains a viable option for patients with rheumatic MV disease and those with functional mitral regurgitation (7-9). Despite its major advantage of low thromboembolic risk without the need for life-long anticoagulation after bioprosthetic MVR, the occurrence of SVD and resultant reoperation during the follow-up is still a major disadvantage.

Efforts have been made to improve the durability of bioprosthetic valves, such as inhibiting calcium phosphate formation, modification of calcifiable material, and 


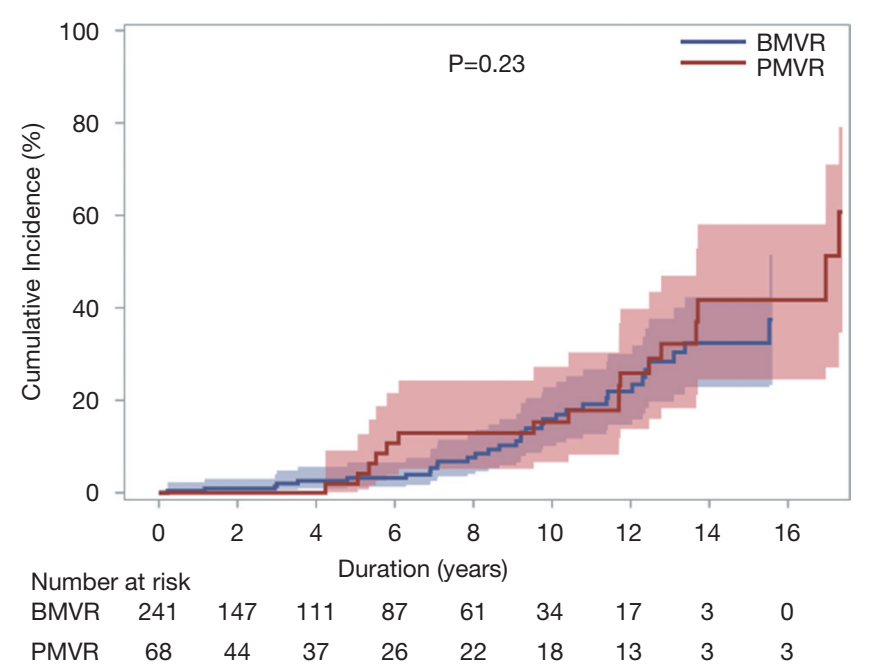

Figure 3 Cumulative incidence function for structural valvular deterioration after MVR with Carpentier-Edwards PERIMOUNT BMVR group and Hancock II PMVR group. The $\mathrm{P}$ value was obtained from multivariable Fine-Gray proportional subdistribution hazards model analysis. MVR, mitral valve replacement; BMVR, mitral valve replacement with CarpentierEdwards PERIMOUNT bovine pericardial valves; PMVR, mitral valve replacement with Hancock II porcine bioprostheses.

improvement of glutaraldehyde fixation (10). In particular, for anticalcification, RESILIA ${ }^{\mathrm{TM}}$ tissue with ethanol rinsing and glycerolization is used for bovine pericardial valves, and $\alpha$-amino oleic acid and surfactant treatment are used for porcine valves (11-14). Several products made of bovine pericardium and porcine valves are available in the market. Numerous studies have shown comparable durability of these two types of bioprostheses in the aortic position $(15,16)$. In the mitral position, however, data directly comparing long-term results after MVR using currently available bovine pericardial and porcine valves are scarce. A previous study demonstrated that the 14-year freedomrate from SVD after bioprosthetic MVR using CarpentierEdwards PERIMOUNT valves was $81.9 \%$ (3). Another study showed a 15 -year freedom-rate from an SVD of $83 \%$ after MVR using Hancock II valves (2). A recent metaanalysis analyzed the occurrence rates of SVD after MVR using several types of tissue valves (17). It revealed that 10 and 15 -year freedom-rates from SVD were $91 \%$ and $61 \%$, respectively, for Carpentier-Edwards pericardial valves, and $84 \%$ and $66 \%$, respectively, for Hancock II porcine valves. However, this meta-analysis was performed indirectly because there were no studies directly comparing MVRs using Carpentier-Edwards and Hancock II bioprostheses. In the present study, these two types of valves were directly compared, and PS-adjusted analyses were performed to minimize bias owing to the retrospective design of this study. The present study showed that the 15-year cumulative incidences of SVD in the BMVR and PMVR groups were $32.4 \%$ and $41.7 \%$, respectively. These might be higher than those reported in the literature because SVD was diagnosed at reoperation or autopsy in the previous studies $(1,2,15,18)$, whereas it was diagnosed using either reoperative findings (4-6). The PS-adjusted multivariable analysis showed no significant differences in the cumulative incidences of SVD between the BMVR and PMVR groups over a period of 18 years after surgery. SVD is caused by intrinsic changes such as leaflet fibrosis, thickening, and calcification (19). A previous study suggested that degeneration in bovine pericardial valve, while it was combined degeneration and leaflet tear in porcine type of valve (20). Although we did not collect detailed data regarding the exact causes of the SVD, 31 out of 33 SVDs resulted in prosthetic valve stenosis or steno-insufficiency in the BMVR group, whereas SVD resulted in stenosis or regurgitation with similar proportions.

The risk factor analyses showed that Euroscore II was a factor associated with various events after MVR including overall survival, SVD and MVRE. Euroscore II is a well-known evaluation tool to predict early mortality after cardiac surgery (21). The present study showed that the Euroscore II also reflected long-term survival after bioprosthetic MVR. Contrary to survival and MVRE, Euroscore II had negative correlation with SVD. This might be due to high probability of death in patients with high Euroscore II, which masked the risk of SVD, although competing risk analysis were performed.

There are several limitations that should be noticed in the present study. First, this was a retrospective study from a single center. Although PS analyses were performed, nonadjustable confounders could have affected the study results. Second, follow-up echocardiography was not performed on a regular basis. Third, in-depth analysis regarding the SVD were limited due to a retrospective nature of the present study; both stenosis and regurgitation of the prosthetic valve were treated as the same SVD and hemodynamic consequence and clinical physical status of patients with SVD were not analyzed further. Fourth, 15-year cumulative incidence of the SVD was not identical between 
Table 5 Univariate and multivariable analyses for the risk factors of mitral valve related events

\begin{tabular}{|c|c|c|c|c|}
\hline Variables $^{a}$ & \multicolumn{2}{|c|}{ Univariate analysis } & \multicolumn{2}{|c|}{ PS-adjusted multivariable analysis } \\
\hline Types of valves & $1.180[0.829-1.679]$ & 0.36 & $1.498[0.975-2.301]$ & 0.065 \\
\hline Body surface area $\left(\mathrm{m}^{2}\right)$ & $0.324[0.105-0.996]$ & 0.049 & $0.357[0.103-1.235]$ & 0.10 \\
\hline Diabetes mellitus & $1.473[1.013-2.140]$ & 0.042 & $0.999[0.645-1.549]$ & 0.99 \\
\hline Coronary artery disease & $1.786[1.118-2.853]$ & 0.015 & 1.477 [0.923-2.365] & 0.10 \\
\hline NYHA class $\geq 3$ & $1.837[1.345-2.509]$ & $<0.001$ & $1.517[1.088-2.117]$ & 0.014 \\
\hline Previous MVR & $1.702[1.141-2.538]$ & 0.009 & $1.069[0.682-1.677]$ & 0.77 \\
\hline Euroscore II & $1.098[1.062-1.135]$ & $<0.001$ & $1.082[1.040-1.125]$ & $<0.001$ \\
\hline
\end{tabular}

a , all variables in Table 1 were analyzed and factors that entered into the multivariable analysis were shown. Cl, confidence interval; COPD, chronic obstructive pulmonary disease; HR, hazard ratio; NYHA, New York Heart Association; MVR, mitral valve replacement; PS, propensity score.

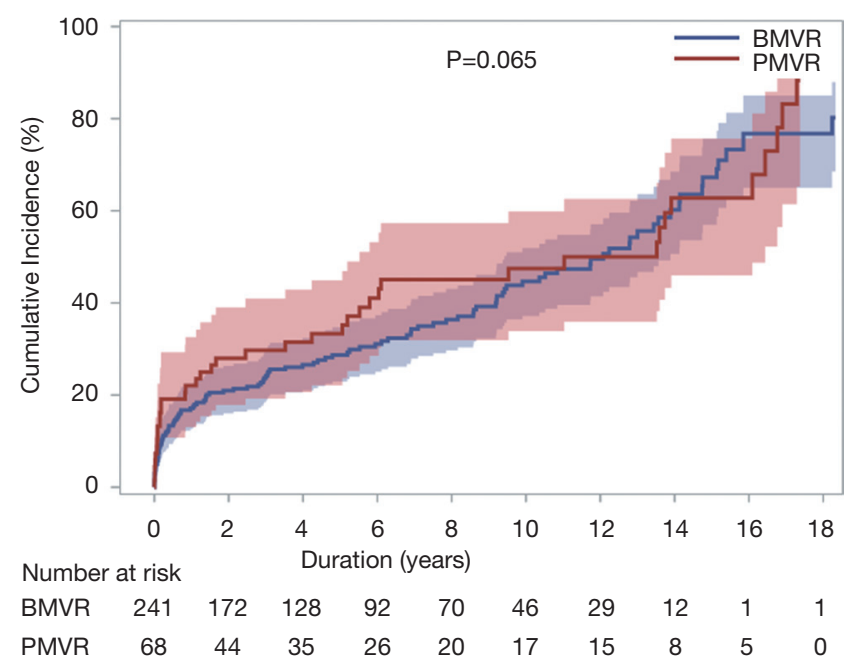

Figure 4 Cumulative incidence function for mitral valve-related events after MVR with Carpentier-Edwards PERIMOUNT BMVR group and Hancock II PMVR group. The $\mathrm{P}$ value was obtained from multivariable Fine-Gray proportional subdistribution hazards model analysis. MVR, mitral valve replacement; BMVR, mitral valve replacement with CarpentierEdwards PERIMOUNT bovine pericardial valves; PMVR, mitral valve replacement with Hancock II porcine bioprostheses.

the two groups, although it was not significant in the PSadjusted multivariable analysis. Further study with longerterm follow-up might be needed to draw definite conclusion.

\section{Conclusions}

The clinical outcomes including overall survival, SVD and MVRE after bioprosthetic MVRs using CarpentierEdwards bovine pericardial and Hancock II porcine valves might not be significantly different for, on average, 7 years of clinical follow-up. Surgeons could select either prosthesis based on their own experiences.

\section{Acknowledgments}

We wish to thank the Medical Research Collaborating Center, Seoul National University Hospital for the statistical analysis and consultation.

Funding: None.

\section{Footnote}

Reporting Checklist: The authors have completed the STROBE reporting checklist. Available at https://dx.doi. org/10.21037/jtd-21-281

Data Sharing Statement: Available at https://dx.doi. org/10.21037/jtd-21-281

Peer Review File: Available at https://dx.doi.org/10.21037/ jtd-21-281

Conflicts of Interest: All authors have completed the ICMJE 
uniform disclosure form (available at https://dx.doi. org/10.21037/jtd-21-281). The authors have no conflicts of interest to declare.

Ethical Statement: The authors are accountable for all aspects of the work in ensuring that questions related to the accuracy or integrity of any part of the work are appropriately investigated and resolved. The study was conducted in accordance with the Declaration of Helsinki (as revised in 2013). The study was approved by the institutional review board of Seoul National University Hospital (IRB No.: 2004-053-111), and the requirement for patient consent was waived.

Open Access Statement: This is an Open Access article distributed in accordance with the Creative Commons Attribution-NonCommercial-NoDerivs 4.0 International License (CC BY-NC-ND 4.0), which permits the noncommercial replication and distribution of the article with the strict proviso that no changes or edits are made and the original work is properly cited (including links to both the formal publication through the relevant DOI and the license). See: https://creativecommons.org/licenses/by-nc-nd/4.0/.

\section{References}

1. David TE, Ivanov J, Armstrong S, et al. Late results of heart valve replacement with the Hancock II bioprosthesis. J Thorac Cardiovasc Surg 2001;121:268-77.

2. Marchand MA, Aupart MR, Norton R, et al. Fifteenyear experience with the mitral Carpentier-Edwards PERIMOUNT pericardial bioprosthesis. Ann Thorac Surg 2001;71:S236-9.

3. Bourguignon T, Espitalier F, Pantaleon C, et al. Bioprosthetic mitral valve replacement in patients aged 65 years or younger: long-term outcomes with the Carpentier-Edwards PERIMOUNT pericardial valve. Eur J Cardiothorac Surg 2018;54:302-9.

4. Akins CW, Miller DC, Turina MI, et al. Guidelines for reporting mortality and morbidity after cardiac valve interventions. Ann Thorac Surg 2008;85:1490-5.

5. Baumgartner H, Falk V, Bax JJ, et al. 2017 ESC/EACTS Guidelines for the management of valvular heart disease. Eur Heart J 2017;38:2739-91.

6. Zoghbi WA, Chambers JB, Dumesnil JG, et al. Recommendations for evaluation of prosthetic valves with echocardiography and doppler ultrasound: a report From the American Society of Echocardiography's
Guidelines and Standards Committee and the Task Force on Prosthetic Valves, developed in conjunction with the American College of Cardiology Cardiovascular Imaging Committee, Cardiac Imaging Committee of the American Heart Association, the European Association of Echocardiography, a registered branch of the European Society of Cardiology, the Japanese Society of Echocardiography and the Canadian Society of Echocardiography, endorsed by the American College of Cardiology Foundation, American Heart Association, European Association of Echocardiography, a registered branch of the European Society of Cardiology, the Japanese Society of Echocardiography, and Canadian Society of Echocardiography. J Am Soc Echocardiogr 2009;22:975-1014; quiz 1082-4.

7. Itzhaki Ben Zadok O, Sagie A, Vaturi M, et al. Long-term outcomes after mitral valve replacement and tricuspid annuloplasty in rheumatic patients. Ann Thorac Surg 2019;107:539-45.

8. Pillai VV, Sreekantan R, Nemani N, et al. Survival and long-term outcomes after concomitant mitral and aortic valve replacement in patients with rheumatic heart disease. Indian J Thorac Cardiovasc Surg 2020;37:1-11.

9. Otto CM, Nishimura RA, Bonow RO, et al. 2020 ACC/ AHA Guideline for the Management of Patients With Valvular Heart Disease: Executive Summary: A Report of the American College of Cardiology/American Heart Association Joint Committee on Clinical Practice Guidelines. Circulation 2021;143:e35-e71.

10. Schoen FJ, Levy RJ. Calcification of tissue heart valve substitutes: progress toward understanding and prevention. Ann Thorac Surg 2005;79:1072-80.

11. Flameng W, Hermans H, Verbeken E, et al. A randomized assessment of an advanced tissue preservation technology in the juvenile sheep model. J Thorac Cardiovasc Surg 2015;149:340-5.

12. Puskas JD, Bavaria JE, Svensson LG, et al. The COMMENCE trial: 2-year outcomes with an aortic bioprosthesis with RESILIA tissue. Eur J Cardiothorac Surg 2017;52:432-9.

13. Duarte IG, MacDonald MJ, Cooper WA, et al. In vivo hemodynamic, histologic, and antimineralization characteristics of the Mosaic bioprosthesis. Ann Thorac Surg 2001;71:92-9.

14. Weber PA, Jouan J, Matsunaga A, et al. Evidence of mitigated calcification of the Mosaic versus Hancock Standard valve xenograft in the mitral position of young sheep. J Thorac Cardiovasc Surg 2006;132:1137-43. 
15. Malvindi PG, Mastro F, Kowalewski M, et al. Durability of mitral valve bioprostheses: a meta-analysis of long-term follow-up studies. Ann Thorac Surg 2020;109:603-11.

16. Wang M, Furnary AP, Li HF, et al. Bioprosthetic aortic valve durability: a meta-regression $\mathrm{f}$ published studies. Ann Thorac Surg 2017;104:1080-7.

17. Hickey GL, Grant SW, Bridgewater B, et al. A comparison of outcomes between bovine pericardial and porcine valves in 38,040 patients in England and Wales over 10 years. Eur J Cardiothorac Surg 2015;47:1067-74.

18. Beute TJ, Goehler M, Parker J, et al. Long-Term outcomes of Mosaic versus Perimount mitral replacements: 17-year follow-up of 940 implants. Ann Thorac Surg

Cite this article as: Kim W, Hwang HY, Kang Y, Kim JS, Sohn SH, Choi JW, Kim KH. Comparative analysis of structural valve deterioration and long-term clinical outcomes after bovine pericardial versus porcine bioprosthetic mitral valve replacement. J Thorac Dis 2021;13(7):3969-3978. doi: 10.21037/ jtd-21-281
2020;110:508-15.

19. Eric Jamieson WR, Marchand MA, Pelletier CL, et al. Structural valve deterioration in mitral replacement surgery: comparison of Carpentier-Edwards supra-annular porcine and perimount pericardial bioprostheses. J Thorac Cardiovasc Surg 1999;118:297-304.

20. Grunkemeier GL, Furnary AP, Wu Y, et al. Durability of pericardial versus porcine bioprosthetic heart valves. J Thorac Cardiovasc Surg 2012;144:1381-6.

21. Chalmers J, Pullan M, Fabri B, et al. Validation of EuroSCORE II in a modern cohort of patients undergoing cardiac surgery. Eur J Cardiothorac Surg 2013;43:688-94. 


\section{Supplementary}

Table S1 Changes in echocardiographic data at preoperative period, early postoperative period and last follow-up (57.8 $\pm 53.3 \mathrm{months})$

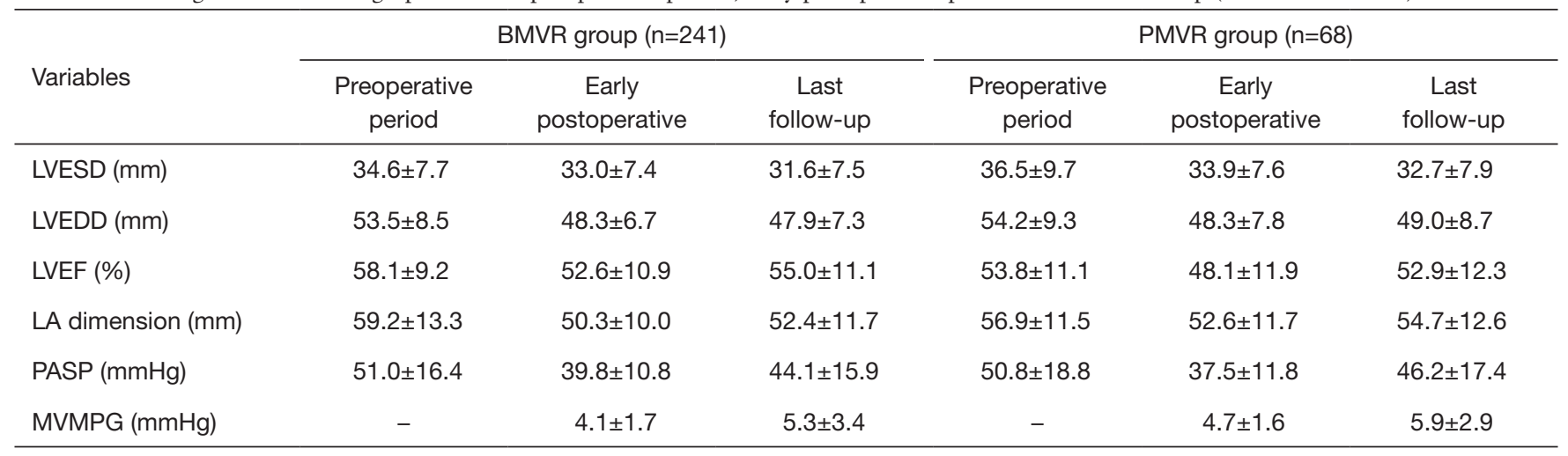

EDD, end-diastolic dimension; EF, ejection fraction; ESD, end-systolic dimension; LA, left atrium; LV, left ventricle; MVMPG, mitral valve mean pressure gradient; PASP, pulmonary artery systolic pressure.

Table S2 Early clinical outcomes

\begin{tabular}{|c|c|c|c|}
\hline Variables & BMVR group $(\mathrm{n}=241)$ & PMVR group $(n=68)$ & P-Value \\
\hline \multicolumn{4}{|l|}{ Complications, n (\%) } \\
\hline Low cardiac output syndrome & $30(12.4)$ & $13(19.1)$ & 0.16 \\
\hline Respiratory complication & $35(14.5)$ & $9(13.2)$ & 0.79 \\
\hline Reoperation due to bleeding & $14(5.8)$ & $9(13.2)$ & 0.040 \\
\hline Stroke & $16(6.6)$ & $3(4.4)$ & 0.78 \\
\hline Mediastinitis & $3(1.2)$ & $2(2.9)$ & 0.30 \\
\hline
\end{tabular}

